\title{
Didàctica de la seguretat
}

\author{
Maria Antònia Merino Calvet \\ Dra. en Ciències Químiques \\ mamerinocalvet@telefonica.net
}

La seguretat en el laboratori passa perquè els alumnes coneguin les normes de seguretat i la forma correcta d'utilització dels instruments i gestió dels residus.

Paraules clau: seguretat al laboratori, normes de seguretat, actituds, residus, instruments

\section{Introducció}

A la literatura específica es troba que "el professor durant la realització del seu treball (la docència), és un treballador que ha de prendre unes normes preventives envers les seves pròpies condicions de treball per la seva pròpia seguretat (físic $i$ personal) $i$ al mateix temps ha de preveure-la envers als que estan al seu voltant (l'alumnat)".

Actualment alguns programes de televisió tracten els experiments de química de forma lúdica, sense cap objectiu didàctic ni pedagògic, presentant la química com un espectacle de llum, color i explosions per la qual cosa seria interessant que tant els alumnes com els professors tinguessin clar quins són els perills i les normes bàsiques de seguritat en la seva actuació desenvolupant la seva activitat en un laboratori d'un centre docent.

Amb la normativa vigent, l'Administració, com a empresa que proporciona un treball, té l'obligació de proporcionar unes condicions de treball adients $\mathrm{i}$ segures, així com de donar la formació necessària a tot el seu personal sobre aquestes qüestions i al mateix temps exigir-li el compliment de les pautes bàsiques de seguretat.

El docent, com a pedagog, ha de formar i donar consciència al seu alumnat de l'existència d'aquestes normes bàsiques preventives, atès que els alumnes són treballadors en potència.

L'aprenentatge conceptual a través del treball experimental és un problema obert tant en la investigació didàctica com en la pràctica docent. El marc teòric en el qual ens basem es recolza en tres aspectes: la formació de conceptes, la naturalesa evolutiva del seu aprenentatge i el paper del pro- fessor en el procés de construcció del coneixement.

El treball pràctic als laboratoris és una eina indispensable en la formació dels nostres alumnes, però no únicament perquè facilita la comprensió dels conceptes que prèviament o posteriorment es veuen a l'aula sinó perquè els posa en contacte amb els objectes i problemes reals del món en què viuen.

Per poder fer un treball de laboratori amb plenes garanties s'ha de poder establir, des d'un bon començament, una planificació que inclogui la seguretat com a contingut dels coneixements.

És inevitable una sistematització i gradació d'aquests coneixements en l'etapa obligatòria i postobligatòria de l'Ensenyament Secundari que tingui com a finalitat la idea que és el propi alumne el que ha de vetllar per la seva pròpia seguretat i exigir al professor, al Centre Docent i a l'Administració, que compleixin la seva quota de responsabilitat.

\section{La finalitat de la seguretat és prevenir els accidents}

La seguretat en el treball dins dels laboratoris és el conjunt de tècniques i procediments que tenen per objectiu eliminar o disminuir el risc que es produeixin els accidents en el treball. No tan sols pel dany que poden produir a les persones sinó també al Medi Ambient.

No es tracta de provocar una "psicosi de seguretat" que impossibiliti la realització de treballs als laboratoris, sinó de formar les persones en els aspectes bàsics que permetin prevenir qualsevol tipus 
d'incident. En aquest sentit és important tractar d'impartir una Educació per a la Seguretat.

Com hem de plantejar el tema d'educar als nostres alumnes en el valor de la seguretat en el treball? Quina metodologia emprem per a assolir la nostra fita?

Hem de tenir amb compte que l'educació per a la seguretat no és una matèria que sé hagi de tractar únicament en l'àrea de Ciències de la Natura, sinó que és una matèria d'ensenyament transversal conjuntament amb l'educació per a la salut.

Quan parlem de "transversalitat" en la prevenció de la seguretat i la salut, volem dir que s'han d'integrar tant en els continguts, els procediments i les actituds, en la totalitat de la vida escolar i en les diverses matèries del currículum acadèmic, com a les vivències dels alumnes en el centre escolar.

En realitat la "transversalitat" és una forma d'ensenyar i d'aprendre.

Els alumnes han de trobar al seu entorn escolar amistós, en el que puguin absorbir uns continguts, uns procediments (hàbits de conducta) i unes actituds que tendeixen a millorar la persona, el grup i la societat en general. Podríem dir que en l'adquisició "inconscient" d'actituds, formes d'interpretar la vida, maneres de veure's a si mateix i de relacionar-se amb l'entorn, és a on intervenim transversalment.

Els riscos que els treballs poden generar són d'índole diversa: des de riscos d'explosió i incendi fins als elèctrics, incloent la toxicitat d'alguns compostos que es fan servir, la pròpia perillositat de l'instrumental si no s'utilitza correctament, així com també qüestions de confort, d'il·luminació i d'ergonomia de les instal-lacions si no són del tot correctes.

No es tracta de complir només unes normes sinó d'assolir un valor: la seguretat, ja que educar no és tan sols donar informació sinó també formar. Es tracta de fer entendre als alumnes, tot reflexionant amb ells, que és necessari interioritzar una sèrie de comportaments que els ajudin a vetllar per la seva pròpia seguretat i la dels seus companys.

Des del vessant del professorat s'ha de tenir en compte que en el transcurs de tota la seva vida laboral estarà exposat durant les pràctiques de laboratori a una sèrie de riscos. I que a llarg termini la salut de les persones que estan exposades a substàncies tòxiques que poden penetrar en el seu organisme a través de les vies respiratòries, l'aparell digestiu o de la pell, pot quedar danyada i desembocar en malalties.

També al laboratori es produeixen reaccions que alliberen grans quantitats d'energia donant Iloc a riscs físics que poden ser importants.

Una manera de prevenir eficaçment aquests efectes és ser extremadament curós en la manipu- lació dels productes químics, reduint-ne al màxim la exposició. Un altre és una formació exhaustiva del professorat sobre temes d'identificació i manipulació de productes químics perillosos, emmagatzematge, eliminació de residus, etc., no només per saber com actuar en defensa de la seva salut laboral sinó també per poder donar als alumnes no sols informació sobre els riscos que es poden trobar, sinó inculcar-los que la seguretat en el treball és un valor i una responsabilitat individual que hauran de preservar al llarg de tota la seva vida.

Ja hem comentat que "un laboratori no és una aula" i que la prevenció dels riscos hi implica una adequació correcta de les instal-lacions i una formació del professorat exhaustiva per tal de poder donar als alumnes no solament informació sobre els riscs que hi poden trobar, sinó també inculcarlos que la seguretat en el treball és un valor i una responsabilitat individual que hauran de preservar al llarg de tota la seva vida.

La primera vegada que els alumnes es posen en contacte amb el laboratori és imprescindible mostrar-los com són les instal-lacions, on es troben els diferents estris i aparells i quines són les seves aplicacions, veure'ls, tocar-los i descriure'ls, no tots de cop, però sí els que faran servir en les properes sessions de pràctiques.

Hem de tenir en compte que les imatges com a recurs didàctic són d'una eficàcia inqüestionable. La paraula i la imatge s'articulen i complementen afavorint i facilitant l'aprenentatge dels alumnes. No podem fer utilitzar un determinat estri o aparell si abans no l'han vist. ("Te digo Sancho que más vale ración de vista que quintales de discursos." Miguel de Cervantes.)

Una altra de les condicions per a un bon aprenentatge eficaç i integrador és la ràtio professor / alumnat. Fóra bo que el nombre d'alumnes per torn de pràctiques i per grup de treball no fos més gran de 14 o 16 per torn i dos per grup, ja que considerant l'edat dels alumnes i amb un sol professor, un nombre més gran d'alumnes no és operatiu.

És millor que els mateixos alumnes s'impliquin i assumeixin responsabilitats prenent el material i, al finalitzar la pràctica, rentant-lo i endreçant-lo. D'aquesta manera el laboratori es trobarà a punt per començar a treballar amb el grup que hi entri desprès.

Un lema serà "el laboratori ha de quedar igual de net $i$ endreçat que com l'has trobat quan hi has entrat", el que fa que es responsabilitzi i impliqui a tots els grups d'alumnes - professor que hi treballen al llarg de tot el curs.

Per poder seguir aquesta dinàmica al laboratori, els alumnes han de disposar d'un coneixement suficient de: 
- les instal-lacions

- el material

- les normes d'actuació

Addicionalment, tots els laboratoris han de disposar d'uns elements de seguretat i complir unes condicions de seguretat determinades.

\section{Característiques essencials d'un laboratori}

Qualsevol laboratori ha de tenir els elements de seguretat en perfectes condicions i en lloc visible i unes condicions de seguretat ben explicitades $i$ d'obligat acompliment.

\section{Elements de seguretat:}

- Equips de lluita contra incendis

- Vitrina extractora de gasos

- Porta de seguretat (dues portes o bé una, que és suficient en cas de pocs alumnes)

- Farmaciola. (aquest element en alguns casos és discutible)

- Contenidor de vidre

- Contenidors de residus

- Possibilitat de lliure circulació per tot l'espai del laboratori

\section{Els alumnes han de tenir coneixement dels elements de seguretat:}

- Com es fan servir els equips de lluita contra incendis.

- Com funciona la vitrina extractora de gasos i en quins casos s'ha de fer servir (si hi ha abundant despreniment de gasos en les reaccions 0 aquets són tòxics)

- Quin és el comportament segur d'actuació: Les dues portes del laboratori han d'estar desblocades i obertes quan s'hi treballa i al finalitzar ell torn de pràctiques, s'han de tancar els llums, les claus generals de pas d'aigua i gas i tancar amb clau les portes. El laboratori romandrà tancat si no s'utilitza.

- Quan i com són els primers auxilis què cal fer i aquí avisar en cas d'accident o d'emergència, quines són les aplicacions del contingut de la farmaciola i com i de quina manera desprès d'un accident cal anar sempre al metge..

- Que els vidres trencats s'han de posar en un contenidor diferenciat del dels residus especials i del de la brossa comuna.

- Com eliminar els residus.

\section{Condicions de seguretat}

- Ordre i netedat

- Mantenir lliure accés als corredors i portes de sortida

- Recollir els vessaments

- Utilitzar contenidors de residus especials

Els alumnes han de conèixer els aspectes següents de les condicions de seguretat:

- Que al laboratori hi ha d'haver ordre i netedat. A les taules de treball no pot haver-hi material innecessari per a l'execució de les pràctiques que s'estan desenvolupant en cada moment.

- Que han de mantenir lliure accés als corredors i portes de sortida per tal que hi hagi, en tot moment, una lliure circulació per tot l'espai del laboratori.

- Que han de recollir immediatament els vessaments que es produeixen i que ho han de fer amb els productes $i$ estris adequats.

- Que no es pot llençar a les aigüeres res que no ho hagi autoritzat el professor/a. Han d'utilitzar els contenidors de residus especials.

- Que la vitrina extractora de gasos no s'ha d'utilitzar mai com a zona d'emmagatzematge de productes.

- Quan finalitzin les pràctiques han de quedar netes les taules de treball i tot el material net i endreçat.

Encara que sigui competència del professor, l'eficàcia en cas d'accident o d'emergència depèn també de que tothom sàpiga què cal fer, a qui avisar i de quina manera.

Després d'un accident mitjanament greu caldrà sempre anar al metge

Un altre requisit important és el coneixement per part dels alumnes dels estris de laboratori, el seu nom, la seva funcionalitat, com s'han de fer servir amb seguretat i la seva ubicació dins del laboratori. El material que es fa servir al laboratori ha d'estar classificat, ordenat i col-locat en calaixos i prestatges adequadament retolats.

Els alumnes trauran i tornaran al seu lloc tot el material que facin servir a cada pràctica, per la qual cosa és força útil donar-los-hi uns fulls amb els dibuixos o fotografies $i$ els noms del material degudament classificat segons:

- material de porcellana

- material de ferro

- material de vidre

- materials diversos

Per conèixer la seva ubicació farem un plànol 
del laboratori on s'indiqui la situació dels armaris i del seu contingut, i el penjarem a totes les parets del laboratori, perquè quan els alumnes tinguin algun dubte sobre la ubicació d'algun estri puguin localitzar-lo fàcilment.

Continuant amb la idea que les imatges són un bon recurs didàctic, i amb l'ajuda de les noves tecnologies informàtiques, es poden fer petits exercicis de reconeixement i assimilació del material del laboratori.

En els ordinadors que estan a disposició dels alumnes, ja sigui als laboratoris -si n'hi ha- o a l'aula d'informàtica, s'hi pot tenir una carpeta que pertany al laboratori de química, de lliure accés pels alumnes, amb planes amb els estris del laboratori, semblant a la que mostrem a continuació.

\section{Material de ferro}

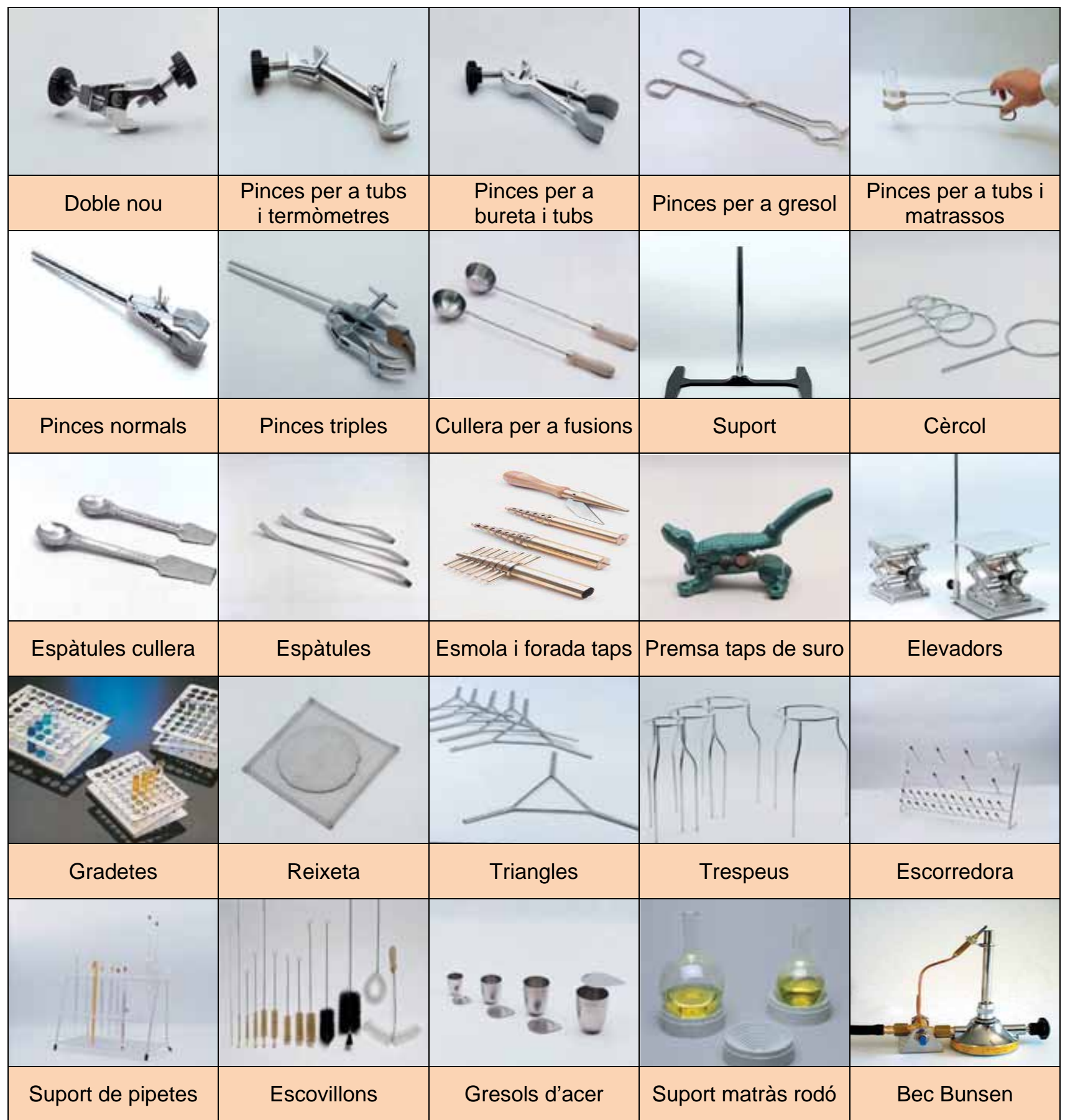


Amb aquest material els alumnes podran resoldre exercicis com el que proposem (vegeu secció suplement d'aquest número). El professor tindrà un nombre infinit de possibilitats de preparar-ne més.

L'ensenyament és més eficaç alternant missatges verbals i icònics o d'imatges ja que en certa manera es complementen: tant el llenguatge de les imatges com el de les paraules són constituïts per signes de diferent naturalesa que també són percebuts de forma diferent. Per això, al laboratori hi ha d'haver tant els símbols de perillositat com les normes de treball al laboratori. I els alumnes han de conèixer-los i tenir-los al seu abast.

En un altre moment comentarem com fer-ho. Enumerarem quines podrien ser aquestes normes i donarem uns recursos didàctics de com els alumnes poden interioritzar-les i recordar-les.

\section{Bibliografia}

ARIAS GARCIA M, CUENCA ALVAREZ, I. (2005). Formación para la prevención. Madrid: Instituto de Nacional de Seguridad e Higiene en el Trabajo. Centro Nacional de Condiciones de Trabajo.
GENERALITAT DE CATALUNYA (2000). La integració de la prevenció en la Docència: Laboratori químic i sanitari. Direcció General de Relacions Laborals. Barcelona: Departament de Treball.

GUTIERREZ BENEITO, M., MIRANDA VILLALBA I, Y OTROS (2002). La seguridad y la salud en el trabajo como materia de enseñanza transversal. Medrid: Instituto de Nacional de Seguridad e Higiene en el Trabajo.

Aquest article es basa en una part del treball de recerca "La seguretat com a valor i norma de treball. La didàctica de la seguretat als laboratoris de Ciències de la Natura en l'ensenyament Secundari".

La seva realització ha estat possible gràcies a una llicència per estudis concedida a la autora per al curs 2005-2006, pel Departament d'Ensenyament de la Generalitat de Catalunya (DOGC número 4471 16/09/2005). 